\section{ESTABLISHING THE NATURE OF FALLS IN CHILDREN IN AN URBAN HOSPITAL IN KENYA TO PREVENT UNINTENTIONAL INJURIES}

Gordon Otieno Odundo. Gertrude's Children's Hospital, Nairobi, Kenya

10.1136/injuryprev-2016-042156.452

Background Nairobi, Kenya has a population of nearly 4 million with an annual growth rate of $4 \%$. However despite the increased urbanisation across the city, healthcare provision ignores unintentional injuries including falls among children and adolescents.

Methods The objective of the study was to establish the nature of falls among children aged 0-21 years presenting at the Gertrude's Children's Hospital Nairobi, Kenya. The study was retrospective based on the review of hospital records from the year 2004 to 2013. The data was analysed based on age group most at risk for a fall, nature of the fall and the cause of the fall injury.

Results A total of 11,137 children were treated for injuries over the study period. Of these, $5570(50 \%)$ sustained fall-related injuries. The number of children admitted for falls annually increased by $332.82 \%$ from 259 in 2004 to 1,121 in 2013. The highest incidence of falls was among the 6-10 year age group ( $\mathrm{n}=2081 ; 37.4 \%$ ) followed by the $11-15$ year age group ( $\mathrm{n}=1502 ; 27 \%)$. The highest number of injuries were sustained by falls on the same ground level ( $\mathrm{n}=2361 ; 42.4 \%$ ), a high place $(\mathrm{n}=884 ; 15.9 \%)$ and from staircases $(\mathrm{n}=776 ; 13.9 \%)$. The least number of injuries were from buildings ( $\mathrm{n}=3 ; 0.05 \%)$ and moving vehicles $(n=2 ; 0.04 \%)$. All injuries were classified by the nature of falls; majority were open and superficial wounds $(\mathrm{n}=2703 ; 48.53 \%)$ and dislocation and strain of joints ( $\mathrm{n}=798 ; 14.3 \%$ ) while the least were intracranial injuries ( $\mathrm{n}=9 ; 0.2 \%)$. Overall falls have not increased more than any other cause of injuries.

Conclusions The clinical setting of a children's hospital allows for easy identification of children most at risk of an unintentional injury. Interventions should be put in place in the communities they live in, and there should be more studies on the causes of fall injuries among children. These injuries may be serious enough to require hospital treatment and even result in disability.

\section{PREVENTION OF UNINTENTIONAL CHILD INJURIES AT HOME: EXPLORING THE PERCEPTION OF IRANIAN POLICYMAKERS}

Atena Barat, Michael Craig Watson, Caroline Mulvaney. The University of Nottingham, UK

\subsection{6/injuryprev-2016-042156.453}

Background Unintentional injury has been the leading threat to health for children in recent years. It remains enormous financial, emotional and social effects on the child and the family, as well as on the community and society as a whole. This study aimed to explore the perception of policymakers to identify their child home injury prevention practices, and to understand barriers and facilitators regarding the prevention of home injuries among children under 5 years. The study focused on Iran due to the paucity of evidence in this area.

Methods An interpretive qualitative approach was adopted for this research. 19 policymakers were selected via a snowball sampling method. They were top-level managers working in variety of organisations concerned with children and could potentially contribute in child safety initiatives. Data were collected through semi-structured interviews. The recorded interviews were transcribed verbatim and inductive thematic analysis was undertaken. Results Policymakers expressed that they were not particularly involved in the prevention of unintentional child injuries in the home setting but they undertook other practices that might indirectly be beneficial in controlling the problem. These practices were providing infrastructures, controlling and supervising, leading and operating activities. Moreover, 9 major themes and 13 subthemes emerged as perceived barriers and facilitators for the issue. Themes that were identified included attitude, injury nature, parents, children, resources, management, market and demographical social change.

Conclusions Child home injury is a complex and multifaceted problem that requires cross-cutting intervention strategies addressing personal, social, structural and political factors. The evidence from this study can contribute to decision-making, developing strategies and generating policies concerning the prevention of child home injuries throughout Iranian healthcare.

\section{UNINTENTIONAL INJURIES FROM BIRTH UP TWO MONTHS: DATA FROM THE ELFE COHORT IN FRANCE}

${ }^{1}$ Anne-Laure Perrine, ${ }^{2,3}$ Corinne Bois, ${ }^{2}$ Marie-Noëlle Dufourg, ${ }^{1}$ Gaëlle Pédrono ${ }^{4}$ Cécile Ricard, 'Bertrand Thélot. 'Santé Publique France, Saint-Maurice, France; ${ }^{2}$ Unité Mixte Elfe-Ined (National Institute for Demographic Studies)-EFS (French Blood Agency), France; ${ }^{3}$ Service Départemental De PMI Des Hauts-De-Seine, Nanterre, France; ${ }^{4}$ Centre Hospitalier Annecy Genevois, France

\subsection{6/injuryprev-2016-042156.454}

Background The Elfe Cohort (French Longitudinal Study of Childhood), consisting of more than 18,000 children recruited in 2011 in French maternity hospitals, aims at better understanding child development, particularly in terms of health and social relations. This cohort will describe familial and environmental risk factors of injuries occurring in children, and analyse the long term outcome of casualties and the prognostic factors for the occurrence of sequelae.

Methods The study focused on 15,869 children included in the Elfe Cohort for whom data were collected at birth and at two months of life. Information was available on the child' socio-cultural context, health, conditions of birth, place of residence, as well as traumatic events in the first two months.

Results During the first two months of life, 73 cases seeking healthcare due to an injury were recorded: 54 consultations and 19 hospitalizations. Head injury was reported in 55 cases. The victims were mostly boys and single children. The socio-demographic characteristics of families were mixed: more precarious and smaller dwellings, parents usually more inactive, mostly French mothers and higher median income. The victims were more likely to sometimes sleep with their parents; they were less often premature ( $2 \%$ vs. $5 \%)$; their mothers were less likely to have consumed alcohol during pregnancy (1\% vs 4\%).

Conclusions These preliminary results will be followed by a detailed description of injuries occurring at 1 year, 2 years of age and beyond, based on the children's growth. The casualties' outcome will be analysed and compared to that of the non-injured. The implications depending on the severity will be compared with data from other surveys. Among data sources on injuries in France (medical administrative bases, population surveys, thematic surveys), the Elfe cohort is the only one that can identify the outcome of injured children. 